\title{
Correction to: Evaluating the relationship between the respiratory exposure to the benzene with the primary damages of deoxyribonucleic acid and total antioxidant capacity in one of the oil companies in Iran
}

\author{
Mohammad Javad Zare Sakhvidi ${ }^{1} \cdot$ Abdorreza Zarei $^{2} \cdot$ Vida Rezaei Hachesu $^{3} \cdot$ Ahmad Zolfaghari $^{4}$ (D)
}

Published online: 8 March 2022

๑) Springer-Verlag GmbH Germany, part of Springer Nature 2022

Correction to: Environmental Science and Pollution Research

https://doi.org/10.1007/s11356-022-19015-2

The format of Tables 2, 3, 4, 5 and 6 are incorrect. The columns on the name of covariates should be on the left side and the corresponding columns about p-values on the right side.

The Original article has been corrected.

Publisher's note Springer Nature remains neutral with regard to jurisdictional claims in published maps and institutional affiliations.

The original article can be found online at https://doi.org/10.1007/ s11356-022-19015-2.

Ahmad Zolfaghari

ahmad_mui@yahoo.com

Mohammad Javad Zare Sakhvidi

mjzs63@gmail.com

Abdorreza Zarei

zarei.tehran@gmail.com

Vida Rezaei Hachesu

vidarezaei93@yahoo.com

1 Occupational Health Department, School of Public Health, Yazd Shahid Sadoughi University of Medical Sciences, Yazd, Iran

2 Occupational Health Department, Health Faculty, Qom University of Medical Sciences, Qom, Iran

3 Occupational Health Department, School of Health, Tehran University of Medical Sciences, Tehran, Iran

4 Faculty of Environment; University of Tehran; Tehran; Iran, Petroleum Industry Health Organization (PIHO), Isfahan, Iran 